\title{
Effect of Exercise Training on Endogenous Stem Cells Activation in Ischemia Reperfusion Induced Skeletal Muscle Injury: A Physio- Histological Study
}

Mira Farouk Youssef ${ }^{1 *}$, Maha Baligh Zickri' ${ }^{1}$, Maha Gamal ${ }^{2}$, Nadia Yassin ${ }^{2}$, Lobna Abd EIAl ${ }^{3}$ and Noha Elhadary ${ }^{3}$

${ }^{1}$ Department of Histology, Faculty of Medicine, Cairo University, Egypt

${ }^{2}$ Department of Physiology, Faculty of Medicine, Cairo University, Egypt

${ }^{3}$ Department of Physiology, Faculty of Pharmacy and Biotechnology, German University in Cairo, Egypt

\begin{abstract}
Background: This study aimed at investigating the possible role of exercise training in activating the migration of CD34 positive progenitor cells in a rat model of induced ischemia reperfusion injury (IRI) of limb skeletal muscle and related regeneration potential.
\end{abstract}

Material and methods: 28 adult male albino rats were divided into three groups: group I: control group; group II: IRI with 2 hours ischemia and 2 hours reperfusion, followed by immediate sacrifice (subgroup Ila) or delayed sacrifice after two weeks (subgroup Illb); group III: exercise in the form of group and gradual swimming for 4 weeks, followed by IRI and immediate sacrifice (subgroup IIla), or delayed sacrifice (subgroup IIlb). Muscle performance was evaluated by physiological tests. Histological study was done using $\mathrm{H} \& \mathrm{E}$ staining, and immunohistochemical staining using anti aSMA and anti CD34. Areas of regenerating fibers, area of aSMA and area percentage of CD34 were measured. Statistical analysis was performed.

Results: IRI group showed severe muscle damage in Ila in the form of wavy, disrupted darkly acidophilic fibers, many dark nuclei, and extravasated blood. There was some improvement in Ilb in the form of regenerating fibres with central nuclei and increased aSMA and CD34 immunostaining. Group III showed better preservation of muscle fibers in IIla. It also showed significant increase in area of regenerating fibers and statistically significant increase in area of aSMA and CD34 and in physiological parameters in IIIb as compared to group II.

Conclusion: Exercise training prior to skeletal muscle IRI markedly improved muscle outcome through preservation and regeneration. Two populations of skeletal muscle stem cells, namely progenitor cells and satellite cells were involved in the process.

Keywords: Skeletal muscle; exercise training; ischemia reperfusion; stem cells

\section{Introduction}

Severe injuries in skeletal muscle result in muscle weakness that delays recovery, which exposes patients to neuromuscular complications that increase hospital stay and mortality [1]. Experimental animal models of tourniquet-induced skeletal muscle injury were exerted and investigated how the injury was influenced by protective means, as antithrombin III administration [2] and microparticles administration in critical limb ischemia [3]. Exercise protocol exerted in a rat model that completed a treadmill training protocol for 12 weeks induced muscle, tendon, and bone adaptations in the rat shoulder [4].

Muscle fibres are classified according to metabolic and contractile properties into fast glycolytic, fast oxidative glycolytic and slow oxidative fibers [ 5]. A lso, there a re three t ypical s keletal $\mathrm{m}$ uscle $\mathrm{c}$ ontractions, namely: isometric (without shortening), concentric (with shortening), and eccentric (with lengthening) contraction. Variable physiological tests are usually combined to effectively test muscle performance [6]. Therapeutic effect of combined training of voluntary an d d ectrical muscle contractions was tested in middle-aged obese women and proved a great potential in improving muscle strength [7].

Satellite cells are resident muscle stem cells, and they express aSMA protein. aSMA is normally expressed in many cells during early stages of their development and differentiation, and gradually disappears with complete maturation. Myofibroblasts developing from granulation tissue fibroblasts transiently expressed aSMA, but not smooth muscle myosin or desmin. Skeletal myoblasts also expressed the protein during early differentiation in culture, while its expression completely disappeared in differentiated fibres [8]. aSMA could be found early in mesothelial stromal cells differentiating into osteogenic or adipogenic lineages [9].

Progenitor cell depletion and increased levels of different mediators linked to endothelial damage, vascular and tissue repair failure were evidenced in rheumatoid arthritis patients [10], A study was designed to examine the hypothesis that circulating CD34 positive progenitor cells play a role in the process of de novo regeneration in human liver transplants, and that these cells arise from a cell population originating in, or associated with, the bone marrow [11].

Consequently, the present study aimed at investigating the possible role of exercise training in activating the migration of $\mathrm{CD} 34$ positive progenitor cells in a rat model of induced ischemia reperfusion injury (IRI) of limb skeletal muscle and related regeneration potential.

*Corresponding author: Mira Farouk Youssef Yacoub, 23 Ibrahim Salem street, off Salah Salem street, Heliopolis, Cairo, Egypt, Tel: +2/01222640868; Fax: +2/24158715 E-mail: mirafaroukyoussef@kasralainy.edu.eg; mira_farouk2@yahoo.com

Received June 06, 2015; Accepted June 17, 2015; Published June 19, 2015.

Citation: Youssef MF, Zickri MB, Gamal M, Yassin N, EIAI LA, et al. (2015) Effect of Exercise Training on Endogenous Stem Cells Activation in Ischemia Reperfusion Induced Skeletal Muscle Injury: A Physio- Histological Study. J Cytol Histol 6: 339. doi:10.4172/2157-7099.1000339

Copyright: (c) 2015 Youssef MF, et al. This is an open-access article distributed under the terms of the Creative Commons Attribution License, which permits unrestricted use, distribution, and reproduction in any medium, provided the original author and source are credited. 


\section{Materials and Methods}

\section{Experimental animals}

Twenty eight male albino rats were used, weighing 200-250 gm and aged on the average 10 weeks. The animals were housed in the Animal House of the German University in Cairo in wire mesh cages at room temperature, with free access to standard diet and excess tap water. The rats were treated in strict accordance with the ethical guidelines approved by the Animal Use Committee of Faculty of Medicine, Cairo University.

\section{Experimental protocol}

The rats were divided into 3 groups classified as follows:

Group (I): The control group: Eight rats were used, 2 for each experimental subgroup. They were not subjected to unilateral limb ischemia.

Group (II): (IRI group): Ten rats were subjected to unilateral limb ischemia for 2 hours followed by reperfusion for another 2 hours $[12,13]$. The rats were further subdivided into 2 subgroups according to the time of sacrifice:

Subgroup IIa: (Immediate sacrifice following IRI): 5 rats sacrificed immediately following reperfusion.

Subgroup IIb: (2weeks recovery following IRI): 5 rats sacrificed 2 weeks following reperfusion.

Group (III): (Exercise and IRI group): Ten rats performed a regular, group and gradual swimming exercise regimen for a period of 4 weeks and then they were subjected to ischemia for 2 hours followed by reperfusion for 2 hours. The rats were further subdivided into 2 subgroups according to time of sacrifice:

Subgroup IIIa: (Immediate sacrifice following exercise and IRI): 5 rats sacrificed immediately following exercise and reperfusion.

Subgroup IIIb: (2weeks recovery following exercise and IRI): 5 rats sacrificed 2 weeks following exercise and reperfusion.

\section{The exercise protocol}

Exercise training was carried out by long-term swim training, over a period of 4 weeks [14]. Subgroups IIIa and IIIb rats were assigned to the exercise protocol, whereas groups I, IIa and IIb rats were restricted to cage activity throughout the training period. Swimming was done in a half-filled cylindrical plastic container, containing water at room temperature. The group swimming method was used, since it promotes more vigorous exercise than when animals are allowed to swim alone [15]. The animals were placed in the container every day at the same time. In each bout, the rats were left to swim in water for about ten minutes. The animal was removed from the water when it was unable to return to the water surface for air, each one independently. After each bout, the rats were very tired but not exhausted, and were able to move around in the cage. Swim training was carried out once per day for one week. Training was increased to twice daily, separated by one hour interval in the 2nd week, to three bouts per day with an hour interval between each bout and the successive one in the 3rd week. In the 4 th week, training was increased to 4 bouts per day with one hour interval [16].

\section{Induction of ischemia reperfusion (IR)}

All animal groups except the control group were subjected to IRI as follows:
Ischemia was achieved by application of an elastic rubber band as high as possible on the left thigh of the rat and ischemic period was 2 hours [12]. After releasing the tourniquet, the limb was reperfused for 2 hours in subgroups IIa and IIIa [17] and for 2 weeks in subgroups IIb and IIIb [18].

\section{Muscle performance physiological parameters}

Before sacrifice, rats were anesthetized with sodium thiopental at a dose of $500 \mathrm{mg} / \mathrm{kg}$ diluted in $5 \mathrm{cc}$ of saline injected intraperitoneal. The left gastrocnemius was isolated from its distal insertion, keeping nerve and vasculature intact for the assessment of the physiological muscle contraction parameters $[19,20]$ which include:

Peak twitch tension (Pt): This is the peak twitch tension in excess of initial tension at optimum length. The left gastrocnemius muscles were stimulated directly through an electrode, with voltage set to gradual increase in the square-wave pulses from $0 \mathrm{~V}$ to $10 \mathrm{~V}$ until producing maximum contraction for $1 \mathrm{~ms}$ duration and $20 \mathrm{~Hz}$ frequency. Recording were displayed at sampling rate $1 \mathrm{~kg} / \mathrm{sec}$ (Newton units)

Peak tetanic tension (PTT): The left gastrocnemius muscles were stimulated by 15 supramaximal pulses, $1 \mathrm{~ms}$ duration with a gradual increase in frequency (from 20 to $50 \mathrm{~Hz}$ ) until the muscle was completely tetanized (measured in Newton units).

Fatigue resistance (FR): The left gastrocnemius muscles were stimulated at $50 \mathrm{~Hz}$ during 2 minutes (sub-maximal continuous tetanus). The duration corresponding to a force decreased by $20 \%$ was noted fatigue resistance (FR) time (measured in seconds).

\section{Dissection of gastrocnemius muscle}

A posterior vertical midline incision in the leg was made and the two skin flaps were reflected medially and laterally exposing the entire gastrocnemius muscle. The two heads of the muscle were dissected carefully from the soleus muscle and sharply from the Achilles tendon [21].

\section{Description of the apparatus}

The electrophysiological measurements were performed using $\mathrm{AD}$ Instruments (Greenwich, CT): Powerlab 4/25 Stimulator which is a four-channel data acquisition system, with recording speeds of up to 200,000 samples/second on one channel with two or four analog input channels and 6-bit resolution. It is also an analog output for stimulation/ pulse generation with wide range of low-pass filters. The Bridge Pod is a signal conditioner designed to work with bridge-type transducers and PowerLab data acquisition systems. The Bridge Pod provides a stable $+2.5 \mathrm{~V}$ excitation source for full-bridge strain-gauge transducers. A $300 \mathrm{~Hz}$ low-pass filter is built-in to reduce signal noise and a manual DC offset adjustment is provided. The muscle was connected to the Powerlab device before and after dissection.

The animals were sacrificed by a lethal dose of ether. Gastrocnemius muscle was exposed and muscle specimens were placed in $10 \%$ formol saline. 5 microns thick sections were prepared and subjected to the following studies:

\section{Hematoxylin and eosin [22] Immunohistochemical Study:}

Anti-alpha smooth muscle actin ( $\alpha S M A)$ : immunostaining: The marker for this antibody stains smooth muscle cells in vessel walls, gut wall, myometrium and myoepithelial cells. Anti-alpha smooth muscle actin antibody (Rabbit polyclonal antibody) (ab5694) was used at a concentration $2 \mu \mathrm{g} / \mathrm{ml}$. Heat mediated antigen retrieval was performed before commencing with IHC staining protocol. Connective tissue 
Citation: Youssef MF, Zickri MB, Gamal M, Yassin N, EIAI LA, et al. (2015) Effect of Exercise Training on Endogenous Stem Cells Activation in Ischemia Reperfusion Induced Skeletal Muscle Injury: A Physio- Histological Study. J Cytol Histol 6: 339. doi:10.4172/2157-7099.1000339

sections containing blood vessels were used as positive control (as shown in results). Cellular localization is the cytoplasm. On the other hand, one of the muscle sections was used as a negative control by passing the step of applying the primary antibody [23].

CD34 immunostaining: is the marker for hematopoietic progenitor cells, small vessel endothelium [24]. CD34 goat polyclonal Ab (SigmaAldrich Chemie Corporation laboratories, Germany, catalogue ID $\mathrm{SAB} 4300690)$. The sections were treated with $\mathrm{CD} 34$, at $15 \mu \mathrm{g} / \mathrm{ml}$ ready to use at room temperature. Cellular localization is the cell membrane. Tonsil sections were used as positive control specimens. On the other hand, one of the muscle sections was used as a negative control by passing the step of applying the primary antibody.

Morphometric study: Using Leica Qwin 500 LTD computer assisted image analysis (Cambridge, United Kingdom), assessment of the area of regenerating muscle fibers (continuous myofibrils without transverse striations) was performed in $\mathrm{H} \& \mathrm{E}$ stained sections using interactive measurements menu. Mean area was studied for anti aSMA, to exclude areas of reaction of smooth muscle of walls of regional blood vessels, while mean area \% was chosen for CD34. The measurements were done in 10 non overlapping high power fields (400X) in control and experimental groups using binary mode.

\section{Statistical analysis}

Quantitative data were summarized as means and standard deviations and compared using one-way analysis-of-variance (ANOVA). Any significant ANOVA was followed by Bonferroni post-hoc test to detect which pairs of groups caused the significant difference. P-values $<0.05$ were considered statistically significant. Calculations were made on statistical package of social science (SPSS) software version 16 [25].

\section{Results}

Muscle Performance Physiological Results are presented in Table 1.

\section{Histological Results}

Control sections revealed longitudinally cut muscle fibers exhibiting peripheral nuclei (Figure1a). Closer observation demonstrated pale oval pale nuclei and transverse striations in the sarcoplasm of the muscle fibers (Figure1b).

In subgroup IIa, multiple muscle fibers appeared wavy, darkly stained acidophilic, and partially segmented by examination of the different fields. Extravasated red blood corpuscles were observed among these fibers (Figure 2a). Closer observation recruited multiple dark nuclei and vacuolations in the sarcoplasm of the darkly stained muscle fibers. Some muscle fibers showed discontinuity of myofibrils along most of the caliber (Figure $2 b$ ).

In subgroup IIb, some muscle fibers appeared wavy, darkly stained acidophilic by examination of the different fields, while few had central

\begin{tabular}{|l|l|l|l|l|l|}
\hline Parameters & Group I & Subgroup lla & Subgroup Illb & Subgroup Illa & Subgroup Illb \\
\hline Pt (N) & $0.29 \pm 0.02$ & $0.09 \pm 0.02^{*}$ & $0.17 \pm 0.02^{* \#}$ & $0.16 \pm 0.02^{* \#}$ & $0.30 \pm 0.03^{\# @ \$}$ \\
\hline PTT (N) & $0.63 \pm 0.07$ & $0.27 \pm 0.05^{*}$ & $0.44 \pm 0.04^{* \#}$ & $0.38 \pm 0.04^{* \#}$ & $0.53 \pm 0.05^{\star \# @ \$ ~}$ \\
\hline FR (sec) & $5.16 \pm 0.46$ & $2.91 \pm 0.59^{*}$ & $\begin{array}{l}3.91 \pm \\
0.66^{* \#}\end{array}$ & $4.25 \pm 0.22^{* \#}$ & $4.81 \pm 0.22^{\# @}$ \\
\hline
\end{tabular}

"Significant compared to group I $(\mathrm{P}<0.05)$.

\#Significant compared to subgroup Ila $(\mathrm{P}<0.05)$.

$@$ Significant compared to subgroup IIb $(\mathrm{P}<0.05)$

$\$$ Significant compared to subgroup IIla $(P<0.05)$.

Table 1: Mean \pm SD Pt, PTT and FR time in group I, subgroups Ila, Ilb, Illa and IIlb.
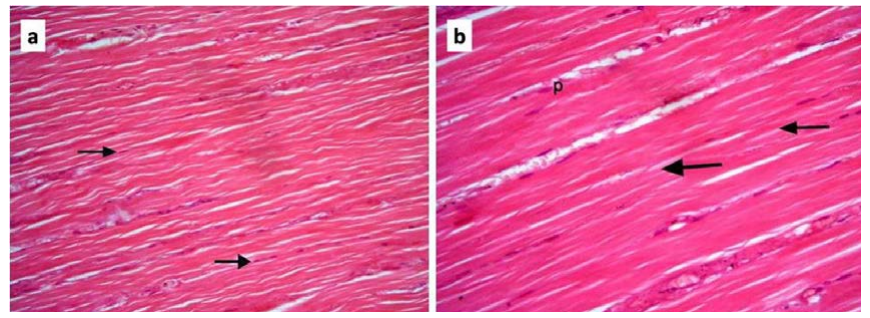

Figure 1: Photomicrographs of skeletal muscle sections of control rats showing: a] longitudinal muscle fibers exhibiting peripheral nuclei (arrows); b] oval pale nuclei (p) and transverse striations (arrows) in the sarcoplasm (H\&E, a 200X; b 400X).
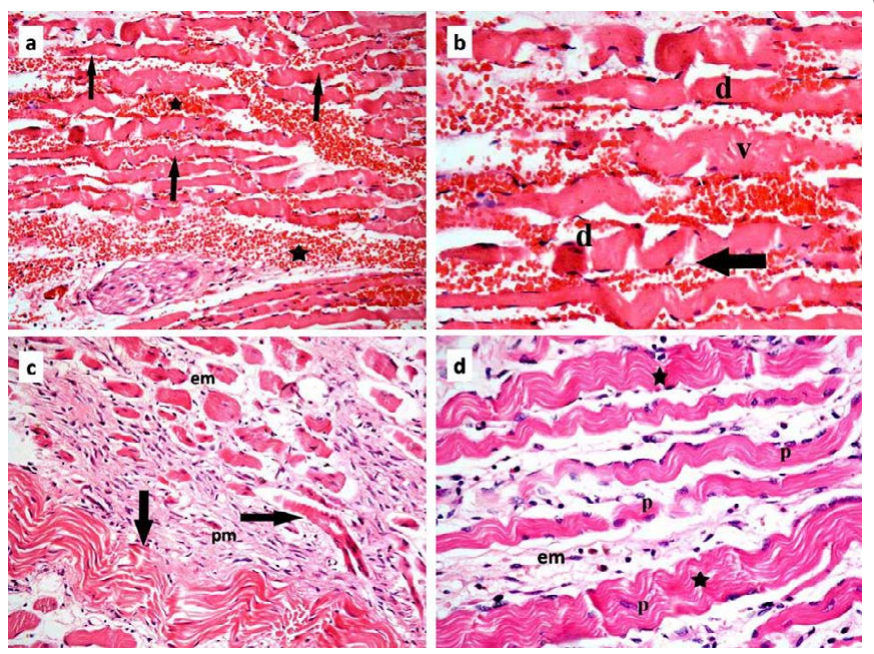

Figure 2: Photomicrographs of skeletal muscle sections of rats in group II showing:

In subgroup Ila: a] extravasated red blood corpuscles $\left(^{*}\right)$ among wavy darkly stained acidophilic and partially segmented muscle fibers (arrows); b] in higher magnification, multiple dark nuclei (d) and vacuolations ( $v$ ) in the sarcoplasm of these fibers, with discontinuous myofibrils through most of its caliber (arrow). In subgroup Ilb: c] some wavy darkly stained acidophilic muscle fibers (arrows). Few fibers have central nuclei. There is increased amount of endomysium (em) and perimysium (pm); d] multiple pale nuclei $(p)$ in the darkly stained fibers. Many myofibrils are continuous but wavy $\left({ }^{*}\right)$ with increased amount of endomysium (em) (H\&E, a and c 200X; b and d 400X).

nuclei. There was also increase in the amount of endomysium and perimysium (Figure 2c). Closer observation recruited multiple pale nuclei and continuous but wavy myofibrils in the sarcoplasm of the darkly stained muscle fibers (Figure 2d).

In subgroup IIIa, occasional darkly acidophilic homogenous muscle fibers appeared among other normal slightly wavy fibers. Obviously congested vessels were seen (Figure 3a). Closer observation recruited fewer dark nuclei. The muscle fibers contained continuous but wavy myofibrils in comparison to subgroup IIa (Figure 3b).

In subgroup IIIb, the muscle fibers appeared normal, and infiltrating cells were detected among the fibers. The blood vessels were less congested. Many fibers exhibited central nuclei (Figure 3c). Closer observation recruited multiple pale nuclei, continuous, straight and parallel myofibrils in the sarcoplasm of the muscle fibers. Transverse striations were detected in localized areas of the sarcoplasm compared to subgroup IIb (Figure 3d).

\section{Immunohistochemical results}

Alpha SMA immunostaining: Skeletal muscle sections of control rats showed positive (+ve) aSMA immunoexpression in the wall 
of arterioles and venules (Figure 4a). Subgroups IIa and IIIa were comparable to control. In subgroup IIb, +ve aSMA immunoexpression was found in the wall of small vessels and few +ve cells were detected in the CT cells between widely spaced muscle fibers. A regenerating fiber with many pale large nuclei could be seen (Figure $4 \mathrm{~b}$ ). In subgroup IIIb, multiple areas revealed +ve aSMA immunoexpression in the wall of few small vessels and some +ve cells appeared in the CT between normal closely arranged muscle fibers compared to subgroup IIb (Figure 4c). Also, few areas demonstrated multiple +ve aSMA cells in the CT between and among disorganized muscle fibers. It was noticeable that some cells overlapping the muscle fibers showed positive reaction, while others did not. Both appeared similar in H\&E sections, and were found different in immunostained sections (Figure $4 \mathrm{~d}$, compared to Figure 3c).

CD 34 immunostaining for progenitor cells: Skeletal muscle sections of control rats revealed negative CD34 immunoexpression among the fibers and the CT in between (Figure 5a). Subgroups IIa and IIIa were comparable to control. In subgroup IIb, some areas demonstrated few +ve spindle cells inside blood vessels and in the CT between more or less regularly arranged fibers (Figure $5 \mathrm{~b}$ ). Some other areas recruited multiple +ve spindle cells in the CT between widely spaced fibers (Figure $5 c$ ). In subgroup IIIb, multiple +ve spindle cells were obvious in multiple areas: inside blood vessels, in the CT between and among normal muscle fibers compared to subgroup IIb (Figure 5d). In few areas, more numerous +ve spindle cells were found in the CT between occasional widely spaced fibers and few +ve cells were seen among the other fibers (Figure 5e).

\section{Morphometric results}

Estimation of the area of regenerated muscle fibers, the area of alpha SMA immunoexpression and the area $\%$ of CD $34+$ ve cells revealed significant increase $(\mathrm{P}<0.05)$ in subgroup IIIb compared to subgroup IIb (Table 2).

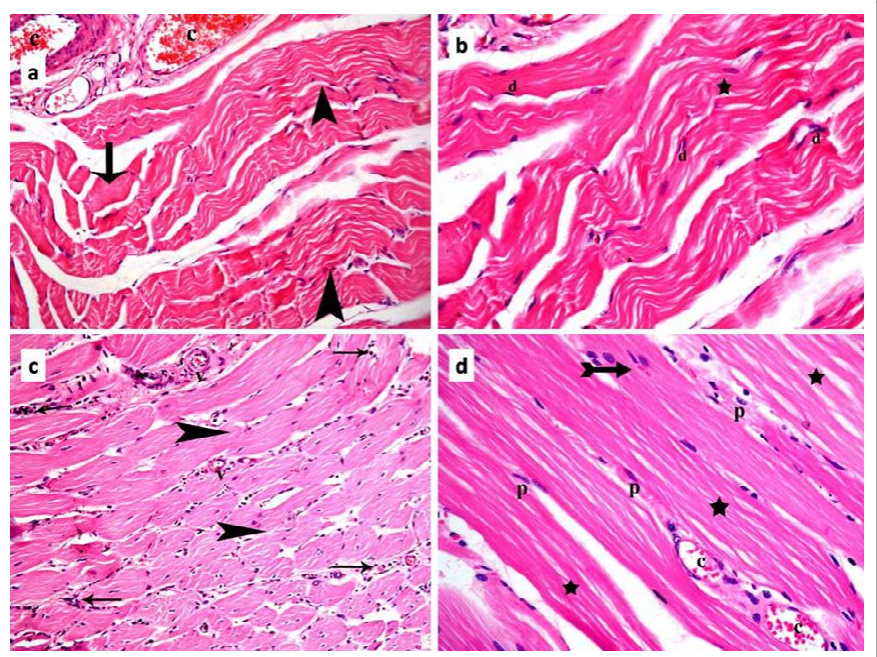

Figure 3: Photomicrographs of skeletal muscle sections of rats in group III showing:

In subgroup IIla: a] a darkly stained acidophilic homogenous muscle fiber (arrow) and other normal slightly wavy fibers (arrowheads), and congested blood vessels (c); b] in higher magnification, fewer dark nuclei (d), and continuous but wavy myofibrils $\left({ }^{*}\right)$ compared to figure $3 \mathrm{~b}$.

In subgroup IIIb: c] normal muscle fibers (arrowheads), infiltrating cells (arrows) among the fibers besides less congested blood vessels (v) compared to $4 a$. Note that many fibers show central nuclei; d] multiple pale nuclei $(p)$ in normal muscle fibers, with continuous, straight and parallel myofibrils $\left({ }^{*}\right)$. An area of the sarcoplasm reveals transverse striations (arrow) and the vessels are less congested (c) (H\&E, a and c 200X; b and d 400X).

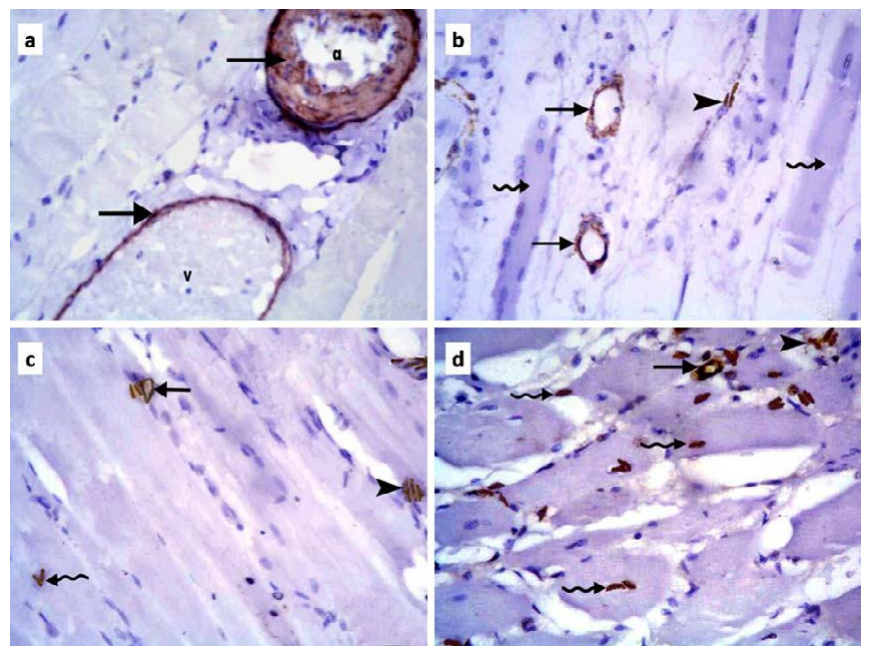

Figure 4: Photomicrographs of skeletal muscle sections of rats in: a] control group showing +ve aSMA immunoexpression (arrows) in the wall of an arteriole (a) and a venule (v);

b] subgroup Ilb showing positive aSMA immunoexpression (arrows) in the wall of two small vessels and in the CT cells between (arrowhead) widely spaced muscle fibers (wavy arrows). Note the regenerating fiber with many large pale nuclei (left wavy arrow);

c] subgroup IIlb showing +ve aSMA immunoexpression (arrow) in the wall of a small vessel and some +ve cells in the CT (arrowhead) between and among (wavy arrow) normal closely arranged muscle fibers compared to $5 \mathrm{~b}$;

d] subgroup IIlb showing +ve aSMA immunoexpression (arrow) in the wall of a small vessel and multiple +ve cells in the CT between (arrowhead) and among (wavy arrow) disorganized muscle fibers. Note that some of the cells that overlapped muscle fibers gave +ve reaction while others did not (as compared to figure 4c). (aSMA immunostaining, 400X).

\section{Discussion}

Regular physical exercise is known to be beneficial to several aspects of individual well being. The present work was done to evaluate the role of training exercise on possible protection, and subsequent regeneration after muscle IRI. Possible mechanisms of muscle protection could be through activation of local as well as distant stem cells.

In the present work, control group showed the characteristic cylindrical arrangement of skeletal muscle fibres, with peripheral pale oval nuclei, and areas of the CT among the fibres. Alpha SMA immunoreactivity was evident in media of regional blood vessels, while CD34 immunoreactivity was negative.

In group IIa (IR and immediate sacrifice), multiple muscle fibers exhibited histological changes. Multiple dark nuclei, vacuolations and discontinuity of myofibrils were seen in the sarcoplasm of the muscle fibers. Extravasated blood was also observed. These histological findings were indicative of commencement of degenerative changes.

Like most forms of tissue injury, ischemia excites an acute inflammatory response that could lead to infarction and tissue death, followed by replacement of necrotic tissue by fibrous tissue, resulting in scarring [26]. Similar changes were also reported by Grounds [27] where they described degenerated myofibers with fragmented cytoplasm. Hypercontracted myofibers were also seen, which could explain the waviness of degenerating fibers found in this work.

Severe congestion of blood vessels with extravasation of blood could be partly due to effect of the tourniquet applied, but mainly due to the 

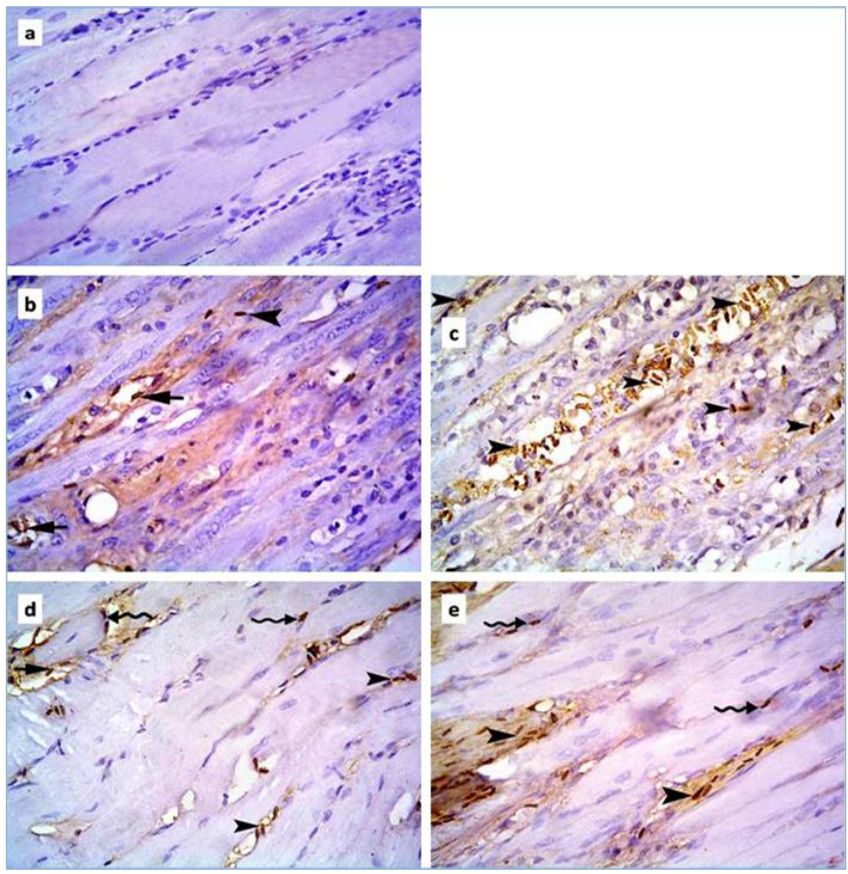

Figure 5: Photomicrographs of skeletal muscle sections of rats in: a] control group showing negative CD34 immunoexpression among the fibers and the CT in between;

b] subgroup llb showing few +ve spindle cells inside blood vessels (arrow) and in the CT between (arrowhead) more or less regularly arranged fibers;

c] subgroup $\mathrm{Ilb}$ showing multiple +ve spindle cells in the CT between (arrowheads) widely spaced fibers;

d] subgroup IIIb showing multiple +ve spindle cells inside a blood vesse (arrow), in the CT between (arrowheads) and among normal muscle fibers (wavy arrows) compared to $6 \mathrm{~b}$ and $6 \mathrm{c}$;

e] subgroup IIIb showing numerous +ve spindle cells in the CT between (arrowheads) occasional widely spaced fibers and few +ve cells among the other fibers (wavy arrows) (CD34 immunostaining, 400X).

\begin{tabular}{|l|l|l|l|}
\hline Groups & $\begin{array}{l}\text { Area of regenerated } \\
\text { fibers }\end{array}$ & $\begin{array}{l}\text { Area of aSMA im- } \\
\text { munoexpression }\end{array}$ & $\begin{array}{l}\text { Area\% of } \\
\text { CD34 immuno- } \\
\text { expression }\end{array}$ \\
\hline Group I & - & $2.06 \pm 0.04$ & - \\
\hline Subgroup Ila & - & - & - \\
\hline Subgroup IIb & $106.74 \pm 9.27$ & $49.38 \pm 11.23$ & $1.32 \pm 0.47$ \\
\hline Subgroup IIIa & - & - & - \\
\hline Subgroup IIIb & $303.38 \pm 19.69^{*}$ & $165.23 \pm 31.07^{*}$ & $7.77 \pm 0.63^{*}$ \\
\hline
\end{tabular}

*significant increase compared to control group and subgroup Ilb.

Estimation of the area of regenerated muscle fibers, the area of alpha SMA immunoexpression and the area\% of $C D$

$34+v e$ cells revealed significant increase $(P<0.05)$ in subgroup IIIb compared to subgroup Ilb.

Table 2: Mean \pm standard deviation (SD) of area of regenerated fibers, area of aSMA and area\% of CD34 immunoexpression in control and experimental groups

IRI. Response to IRI could result in leucocyte dependent microvascular injury that is part of multiple organ dysfunction syndrome [28]. This could thus contribute to the severe extent of vascular injury seen in this group. This could be part of the acute inflammatory response, or injury resulting in degenerative changes followed by inflammatory response [29] to clean dead tissue.

Many surgical procedures, such as limb revascularization and freeflap reconstruction, involve prolonged ischemia of skeletal muscle. Ischemic damage results from a decrease in the blood flow of the organ, and reperfusion injury results from the enhanced generation of oxygen radicals [30]. The mechanism of hypoxia/ reoxygenation injury in human skeletal muscle was suggested to involve opening of the mitochondrial permeability transition pore and depletion of ATP synthesis [31]. This is accompanied by an increase in insulin binding capacity of insulin receptors in skeletal muscle, a decrease in insulin level and an increase in the concentration of glucose in blood serum [32]. It could be commented that the muscle lacks sufficient energy source.

Acute severe muscle injury causes release of large amounts of reactive oxygen species (ROS) that can exceed the ability of antioxidant enzymes in the tissue. ROS can trigger variable responses ranging from adaptation up to cell death, according to level and rate of production. ROS are useful signaling molecules if generated in gradual physiological levels. Beyond such levels they have toxic effects [33]. Skeletal muscle ischemia initiates muscle cell apoptosis and necrosis leading to the release of endogenous ligands. These ligands activate Toll like receptors which are the key receptors of the innate immune system. This leads to release of proinflammatory cytokines, chemokines and apoptosis [34].

In group IIb (IR and sacrifice after 2 weeks), some muscle fibers were affected when examining the different fields. Some pale nuclei and continuous but wavy myofibrils in the sarcoplasm of the affected fibers were recruited. Few fibres exhibited central nuclei. These morphological changes were indicative of commencement of minimal regenerative changes. Regenerating fibers are difficult to distinguish from recently degenerated fibers. Regenerating ones are however identified by being plumper and having central nuclei [27].

The risk of muscle necrosis must be considered when managing arterial injuries, in such cases as free flap reconstruction, particularly if trials of revascularization are unsuccessful. Every effort should be made to optimize repair technique. Fully viable muscle is necessary to restore function and livelihoods [35]. Many factors affect regeneration following IRI, as increased vascular endothelial growth factor production which significantly increased the capillary bed and promoted regeneration [36]. Also, accumulation of hydrogen peroxide following ischemia caused upregulation of osteopontin in the muscle tissue, which is a critical mediator of postischemic neovascularization, and thus a therapeutic target [37].

Increased endomysium and perimysium was clearly noticed in group IIb, as fibrosis is part of the response to muscle injury and incomplete recovery. In group IIIb however area of CT was visibly less, which indicated more complete recovery, and preservation of the muscle fibers. This was also noted in work done by Grounds [27]

In group IIIa, fewer dark acidophilic muscle fibers appeared among multiple normal fibers. Obviously congested vessels were seen. Fewer dark nuclei were recruited. The muscle fibers contained continuous but wavy myofibrils in comparison to group IIa. It could be concluded that less muscle damage detected by immediate sacrifice can be referred to training exercise.

Protective effect of exercise may have several mechanisms. The protective effect of remote ischemic preconditioning was tested, where exposure of certain tissues as lung, to brief cycles of non-lethal IR had protective effects on same and remote tissues as the heart [38]. This could be similar to the changes that occur at the onset of training, where lactate accumulation after relative tissue ischemia could upregulate similar tolerance to subsequent injury. Inflammatory response is pronounced after unaccustomed exercise. Regular training however may help to normalize this response [39]. It was recorded that exercise 
promoted transitory alterations in cytokine secretion, and these changes were affected by exercise duration and intensity. The plasma cytokine levels were evaluated after exercise in mice, where increased IL- 6 and monocyte chemotactic protein-1 levels suggested an adequate inflammatory milieu to induce muscle regeneration [40].

Physical training probably exerted its positive effect through the gradual increases in the levels of ROS, leading to gradual tolerance through induction of antioxidant enzymes as superoxide dismutase, catalase and glutathione peroxidase, thus promoting the positive effect of ROS in the tissue [33].

In group IIIb, the muscle fibers appeared more or less normal and the blood vessels were not congested. Multiple pale nuclei and continuous myofibrils in the muscle fibers were recruited. Some fibres had central nuclei. Some of these nuclei were positive for aSMA, which meant they were satellite cells overlapping the fibers. Other nuclei were negative for aSMA denoting they were actual regenerating cell nuclei. Reduction in the percentage of fibres having central nuclei could express full recovery and organization [41]. Transverse striations were detected in localized areas of the sarcoplasm compared to group IIb though not as in the control group. Histological findings were coherent with the physiological parameters measured for the different fiber types, where muscle performance was significantly improved in group IIIa when compared to the IIa. Muscle performance was also significantly improved two weeks after IRI in group IIIb than in group IIb. It could be concluded that less muscle damage detected by delayed sacrifice can be referred to training exercise.

This beneficial protective effect of exercise could be expected by other researchers studying pregnancy- induced physiological hypertrophy of smooth muscle, and swimming - induced physiological hypertrophy of skeletal muscle. Both protected against IRI and activated cardiac progenitor cells $[42,43]$. On the other hand, disuse atrophy of skeletal muscle also affected satellite cells and myonuclei through molecular signaling pathways and through responsiveness to myostatin and growth factors [44]. This proved that satellite cells and myonuclei were integrally involved in skeletal muscle responses to environmental changes that induce atrophy or possibly hypertrophy. Thus, exercise would have positive effect on both the muscle and its satellite and progenitor cells. It was also proved that the chronic moderate exercise positively altered the systemic glucose homeostasis, enhanced the insulin action, and ameliorated the oxidative damage in the skeletal muscle [45]. Interestingly, physical exercise programs are applied to reduce skeletal muscle loss in cancer cachexia [46].

In the present work, two populations of stem cells were detected by using anti CD34 immunostaining for non-committed (progenitor) cells, and anti aSMA for committed muscle stem cells (satellite cells). Results showed statistically significant increase in aSMA area in group IIb denoting some regeneration that occurred with time. In group IIIb, however, staining was significantly more than in group IIb, denoting significant increase in satellite cell population and consequently muscle regeneration. This clearly indicated active regeneration in the exercise training group.

Comparative results for CD34 were also found. Group IIIb exhibited more CD34 +ve spindle cells than group IIb and control. These cells were seen inside blood vessels denoting migration, and between the fibres. Areas where fibres were deranged had more +ve cells, while areas where fibres were relatively organized housed less CD34 +ve cells. It could be concluded that exercise training enhanced migration of stem cells to muscle tissue exposed to injury. Areas that showed less +ve cells could be related to more complete restoration of histological structure. Absence of CD34 positivity in vessels in control sections supports that all + ve cells found are probably migrating cells.

Alfaro et al. [47] considered that CD34 beyond being a stem cell marker may play an important function in modulating stem cell activity. Other researchers noted a minority of satellite cells lacking CD34 [48], while yet others documented satellite cells within adult skeletal muscle as an enriched population of CD34+ve cells [49]. They were proved responsible for the regenerative potential of skeletal muscle [50].

Muscle stem cells are affected by all factors of the stem cell niche which is the specialized microenvironment found within the tissue, that influences activities of these cells. This niche can at times be described as quiescent niche, or as activated niche. It includes: the myofibres and the basal lamina that is in contact with the satellite cells, interstitial cells, cells of immune system, as well as cells of the vasculature, and factors secreted by many of these elements. More distant factors affecting this niche would be neural- mediated trophic factors, electrical activity, and systemic factors present in the circulation. The atrophying myofiber was found to communicate altered signals to the stem cells. Also, composition of the local milieu changed with increase in CT components, remodeling of neuromuscular junctions, and functional changes involving apoptosis or impaired chemotaxis [51]. Training exercise would thus be an important factor causing activation of many elements of this stem cell niche as increased electrical activity, myofiber thickness, as well as microvessel formation and endothelial activity. This would explain the marked improvement of muscle histological appearance in the exercised group, both due to preservation, as well as regeneration.

After trauma, satellite cells were found to leave their quiescent stage to enter the cell cycle and undergo multiple rounds of proliferation, a process regulated by many factors, aiming to initiate differentiation, fusion and maturation of new skeletal muscle fibers [52].

The present work thus proved an extended value for muscle training exercise that goes beyond immediate improvement of muscle performance. This could be employed in many situations to improve or correct quality of life, when applicable. Exercise programs applied in management of cancer cachexia [46] possibly affect both the muscle fibers as well as the muscle stem cells. Exercise is also valuable for diabetic patients to control and compensate muscle loss, particularly for the younger ones [53].

Study limitations faced involved mainly the time selected for delayed sacrifice. Examining the tissue changes one week after IRI could give more results on the process. Four weeks later could also show maximum level of recovery reached, or level of persistent injury. These were not feasable due to limited number of expermental animals.

Furthur work is needed to characterize and label muscle progenitors. Research work is currently studying isolation and culturing of skeletal muscle progenitors from the satellite cell pool using negative and positive selection markers [54] for further therapeutic use. One of the means to characterize and isolate these cells therefore would be through CD34 immunostaining characteristics, prior to development of aSMA immunoreaction.

This work concluded that exercise training prior to skeletal muscle IRI markedly improved muscle outcome through preservation and regeneration. Two populations of skeletal muscle stem cells, namely progenitor cells and satellite cells, showing varying patterns of distribution and immunostaining characteristics, were involved in the process. 
Citation: Youssef MF, Zickri MB, Gamal M, Yassin N, EIAI LA, et al. (2015) Effect of Exercise Training on Endogenous Stem Cells Activation in Ischemia Reperfusion Induced Skeletal Muscle Injury: A Physio- Histological Study. J Cytol Histol 6: 339. doi:10.4172/2157-7099.1000339

Page 7 of 8

\section{References}

1. Olivera F, Bevilacqua LR, Anaruma CA, Boldrini Sde C, Liberti EA (2010) Morphological changes in distant muscle fibers following thermal injury in Wistar rats. Acta Cir Bras 25: 525-528.

2. Karamanos D, Karkos C, Kambaroudis A, Kritsepi M, Papadopoulos S, et al (2014) The effect of Antithrombin-III on routine hematological and biochemical parameters in an experimental animal model of skeletal muscle ischemiareperfusion injury. Hippokratia 18: 234-239.

3. Sheu JJ, Lee FY, Wallace CG, Tsai TH, Leu S, et al. (2015) Administered circulating microparticles derived from lung cancer patients markedly improved angiogenesis, blood flow and ischemic recovery in rat critical limb ischemia. $J$ Transl Med 13: 59

4. Rooney SI, Loro E, Sarver JJ, Peltz CD, Hast MW, et al. (2015) Exercise protocol induces muscle, tendon, and bone adaptations in the rat shoulder. Muscles Ligaments Tendons J 4: 413-419.

5. Maclntosh BR, Gardiner PF and McComas AJ (2006) Skeletal Muscle: Form and Function. Human Kinetics Champagne, Illinois.

6. Morrissey D, Roskilly A, Twycross-Lewis R, Isinkaye T, Screen H, et al. (2011) The effect of eccentric and concentric calf muscle training on Achilles tendon stiffness. Clin Rehabil 25: 238-247.

7. Oh S, Maruyama T, Eguchi K, Shida T, Arai E, et al. (2015) Therapeutic effect of hybrid training of voluntary and electrical muscle contractions in middle-aged obese women with nonalcoholic fatty liver disease: a pilot trial. Ther Clin Risk Manag 11: 371-380.

8. Springer ML, Ozawa CR, Blau HM (2002) Transient production of alpha-smooth muscle actin by skeletal myoblasts during differentiation in culture and following intramuscular implantation. Cell Motil Cytoskeleton 51: 177-186.

9. do Amaral RJ, Benac P, Andrade LR, Farina M, Bernardazzi C, et al. (2015) Peritoneal Submesothelial Stromal Cells Support Hematopoiesis and Differentiate into Osteogenic and Adipogenic Cell Lineages. Cells Tissues Organs

10. Rodríguez-Carrio J, Alperi-López M2, López P, Alonso-Castro S2, CarroEsteban SR, et al. (2015) Red cell distribution width is associated with endothelial progenitor cell depletion and vascular-related mediators in rheumatoid arthritis. Atherosclerosis 240: 131-136.

11. Lee SG, Moon SH, Kim HJ, Lee JY, Park SJ, et al. (2015) Role of bone marrowderived progenitor cells in de novo liver regeneration in human liver transplants. Liver Transpl.

12. Prem JT, Eppinger M, Lemmon G, Miller S, Nolan D, et al. (1999) The role of glutamine in skeletal muscle ischemia/reperfusion injury in the rat hind limb model. Am J Surg 178: 147-150.

13. Karakoyun R, Koksoy C, Yilmaz TU, Altun H, Banli O, et al. (2014) The angiogenic effects of ischemic conditioning in experimental critical limb ischemia. Eur J Vasc Endovasc Surg 47: 172-179.

14. Goessler KF, Martins-Pinge M, Veronez da Cunha N, Karlen-Amarante $\mathrm{M}$, de Andrade FG, et al. (2014) Treatment with nebivolol combined with physical training promotes improvements in the cardiovascular responses of hypertensive rats. Can J Physiol Pharmacol 92: 234-242.

15. Silva E, Natali AJ, Silva MF, Gomes GJ, Cunha DN, et al. (2013) Ventricula remodeling in growing rats with experimental diabetes: The impact of swimming training. Pathol Res Pract 209: 618-626.

16. de Lemos ET, Reis F, Baptista S, Pinto R, Sepodes B, et al. (2007) Exercise training is associated with improved levels of $C$-reactive protein and adiponectin in ZDF (type 2) diabetic rats. Med Sci Monit 13: BR168-174.

17. Atahan E, Ergun Y, Belge Kurutas E, Cetinus E, Guney Ergun U (2007) Ischemia-reperfusion injury in rat skeletal muscle is attenuated by zinc aspartate. J Surg Res 137: 109-116.

18. Rácz IB, Illyés G, Sarkadi L, Hamar J (1997) The functional and morphological damage of ischemic reperfused skeletal muscle. Eur Surg Res 29: 254-263.

19. Vignaud A, Hourde C, Medja F, Agbulut O, Butler-Browne G, et al. (2010) Impaired skeletal muscle repair after ischemia-reperfusion injury in mice. J Biomed Biotechnol 2010: 724914

20. Tallis J, Higgins MF, Cox VM, Duncan MJ, James RS (2014) Does a physiological concentration of taurine increase acute muscle power output, time to fatigue, and recovery in isolated mouse soleus (slow) muscle with or without the presence of caffeine? Can J Physiol Pharmacol 92: 42-49.

21. Hendy A, Allam A, Abdel-Khalek A, Zayed E, Abdel-Razek S, et al. (2003) Split Gastrocnemius muscle flap. Egypt J. Plast. Reconstr. Surg 27: 181-187.

22. Kiernan JA (2001) Histological and histochemical methods: theory and practice (3rdedn.) Arnold Publishers, London, New York.

23. Elia A, Charalambous F, Georgiades $P$ (2011) New phenotypic aspects of the decidual spiral artery wall during early post-implantation mouse pregnancy. Biochem Biophys Res Commun 416: 211-216.

24. Zhou JH, Cao LH, Liu JB, Zheng W, Liu M, et al. (2011) Quantitative assessment of tumor blood flow in mice after treatment with different doses of an antiangiogenic agent with contrast-enhanced destruction-replenishment US. Radiology 259: 406-413.

25. Emsley R, Dunn G, White IR (2010) Mediation and moderation of treatment effects in randomised controlled trials of complex interventions. Stat Methods Med Res 19: 237-270.

26. Stevens A, Lowe JS, Young B (2003) Wheater's Basic Histopathology. A colou atlas and text (4thedn.) Churchill Livingstone, Edinburgh, London, New York.

27. Grounds M (2014) Quantification of histopathology in Hematoxylin and Eosin stained muscle sections. Treat NMD. Neuromuscular network. DMD_M.1.2.007: 1-13.

28. Carden DL, Granger DN (2000) Pathophysiology of ischaemia-reperfusion injury. J Pathol 190: 255-266.

29. Gillani S, Cao J, Suzuki T, Hak DJ (2012) The effect of ischemia reperfusion injury on skeletal muscle. Injury 43: 670-675

30. Sotoudeh A, Takhtfooladi MA, Jahanshahi A, Asl AH, Takhtfooladi HA, et al. (2012) Effect of $\mathrm{N}$-acetylcysteine on lung injury induced by skeletal muscle ischemia-reperfusion. Histopathlogical study in rat model. Acta Cir Bras 27 168-171.

31. Naparus A, Ashrafpour H, Hofer SO, Zhong T, Huang N, et al. (2012) Efficacy and mechanism of hypoxic postconditioning in salvage of ex vivo human rectus abdominis muscle from hypoxia/reoxygenation injury. Eur J Pharmacol 686: 90-96.

32. Krauss H, Bogdański P, Sosnowski P, Suliburska J, Jabłecka A, et al. (2012) Influence of short-term L-arginine supplementation on carbohydrate balance in rats with ischemia-reperfusion syndrome. Pharmacol Rep 64: 635-642.

33. Barbieri E, Sestili $P$ (2012) Reactive oxygen species in skeletal muscle signaling. J Signal Transduct 2012: 982794

34. Patel H, Shaw SG, Shi-Wen X, Abraham D, Baker DM, et al. (2012) Toll-like receptors in ischaemia and its potential role in the pathophysiology of muscle damage in critical limb ischaemia. Cardiol Res Pract 2012: 121237.

35. Lowrie AG, Berry MG, Kirkpatrick JJ, Lees VC, McGrouther DA (2012) Arteria injuries at the elbow carry a high risk of muscle necrosis and warrant urgent revascularisation. Ann R Coll Surg Engl 94: 124-128.

36. Louboutin JP, Marusich E, Gao E, Agrawal L, Koch WJ, et al. (2012) Ethano protects from injury due to ischemia and reperfusion by increasing vascularity via vascular endothelial growth factor. Alcohol 46: 441-454

37. Lyle AN, Joseph G, Fan AE, Weiss D, Landázuri N, et al. (2012) Reactive oxygen species regulate osteopontin expression in a murine model of postischemic neovascularization. Arterioscler Thromb Vasc Biol 32: 1383-1391.

38. Lim SY, Hausenloy DJ (2012) Remote ischemic conditioning: from bench to bedside. Front Physiol 3: 27.

39. Della Gatta PA, Garnham AP, Peake JM, Cameron-Smith D (2014) Effect of exercise training on skeletal muscle cytokine expression in the elderly. Brain Behav Immun 39: 80-86.

40. Campi-Azevedo AC, Cleto LS, Silva RS, Sousa-Franco Jd, Magalhães JC et al. (2011) Divergent cytokine response following maximum progressive swimming in hot water. Cell Biochem Funct 29: 610-616.

41. Corona BT, Rathbone CR (2014) Accelerated functional recovery after skeletal muscle ischemia-reperfusion injury using freshly isolated bone marrow cells. Surg Res 188: 100-109.

42. Xiao J, Li J, Xu T, Lv D, Shen B2, et al. (2013) Pregnancy-induced physiologica hypertrophy protects against cardiac ischemia-reperfusion injury. Int J Clin Exp Pathol 7: 229-235.

43. Xiao J, Xu T, Li J, Lv D, Chen P, et al. (2014) Exercise-induced physiologica 
Citation: Youssef MF, Zickri MB, Gamal M, Yassin N, EIAI LA, et al. (2015) Effect of Exercise Training on Endogenous Stem Cells Activation in Ischemia Reperfusion Induced Skeletal Muscle Injury: A Physio- Histological Study. J Cytol Histol 6: 339. doi:10.4172/2157-7099.1000339

Page 8 of 8

hypertrophy initiates activation of cardiac progenitor cells. Int J Clin Exp Pathol 7: 663-669.

44. Brooks NE, Myburgh KH (2014) Skeletal muscle wasting with disuse atrophy is multi-dimensional: the response and interaction of myonuclei, satellite cells and signaling pathways. Front Physiol 5: 99.

45. Krskova K, Eckertova M, Kukan M, Kuba D, Kebis A, et al. (2012) Aerobic training lasting for 10 weeks elevates the adipose tissue FABP4, Gia, and adiponectin expression associated by a reduced protein oxidation. Endocr Regul 46: 137-146.

46. Madeddu C, Maccio A, Mantovani G (2012) Multitargeted treatment of cancer cachexia. Crit Rev Oncog 17: 305-314.

47. Alfaro LA, Dick SA, Siegel AL, Anonuevo AS, McNagny KM, et al. (2011) CD34 promotes satellite cell motility and entry into proliferation to facilitate efficient skeletal muscle regeneration. Stem Cells 29: 2030-2041.

48. leronimakis N, Balasundaram G, Rainey S, Srirangam K, Yablonka-Reuveni Z, et al. (2010) Absence of CD34 on murine skeletal muscle satellite cells marks a reversible state of activation during acute injury. PLoS One 5: e10920.
49. Pasut A, Oleynik P, Rudnicki MA (2012) Isolation of muscle stem cells by fluorescence activated cell sorting cytometry. Methods Mol Biol 798: 53-64.

50. Di Foggia V, Robson $L$ (2012) Isolation of satellite cells from single muscle fibers from young, aged, or dystrophic muscles. Methods Mol Biol 916: 3-14.

51. Gopinath SD, Rando TA (2008) Stem cell review series: aging of the skeletal muscle stem cell niche. Aging Cell 7: 590-598.

52. Al-Sawaf O, Fragoulis A, Rosen C, Keimes N, Liehn EA, et al. (2014) Nrf2 augments skeletal muscle regeneration after ischaemia-reperfusion injury. J Pathol 234: 538-547.

53. D'Souza DM, Al-Sajee D, Hawke TJ1 (2013) Diabetic myopathy: impact of diabetes mellitus on skeletal muscle progenitor cells. Front Physiol 4: 379 .

54. Bareja A, Holt JA, Luo G, Chang C, Lin J, et al. (2014) Human and mouse skeletal muscle stem cells: convergent and divergent mechanisms of myogenesis. PLoS One 9: e90398. 